\title{
THE USE OF RESPONSE TOKENS IN WAITING FOR GODOT BY SAMUEL BECKETT
}

\author{
Muhammad Izzul Islam ${ }^{1}$, Murni Fidiyanti ${ }^{2}$, Rezkiawati Nazaruddin ${ }^{3}$ \\ State Islamic University of Sunan Ampel Surabaya ${ }^{12}$, Universitas Sulawesi Barat ${ }^{3}$ \\ Zzlislam5@gmail.com ${ }^{1}$, murni1fidiyanti@yahoo.com ${ }^{2}$, keenadin@gmail.com ${ }^{3}$
}

\begin{abstract}
This study discusses the use of response tokens in Waiting for Godot written by Samuel Beckett. Specifically, it examines kinds and the functions of response tokens uttered by the main characters. This research uses descriptive approach to obtain rich description and to understand response tokens in Waiting for Godot. The data were taken form Vladimir's and Estragon's utterances. The key findings suggest that the types of response tokens in the drama are single response token, response token preceding expanded response, premodified response token, negative token and doublet and also triplet token. Meanwhile, the functions of response token include the function of continuers, acknowledgement, newsmarker, change-ofactivity, assessement and brief question token.
\end{abstract}

Keywords: response tokens; Waiting for Godot

\section{INTRODUCTION}

In everyday communication, sometimes we find a listener who does not clearly attend to the speaker. This situation can be annoying for the speaker and can effect on the bad relationship. Hence, it is important for the listeners to give some signals which indicating that he/she pays attention to the speaker, for example, the use of response tokens like yeah or oh. By uttering response tokens, the speaker will think that he/she is respected.

Harris et al. (1975) said that giving those signals' function is not only as constructing and consolidating social relations but as strategic mechanisms for creating transitions into and out of transactional talk. Schiffrin (1987) gives an example of a token 'oh' which is used to mark transitions in information states of speakers. This mechanism is also explained by McCarthy (2003) who stated that the responses are not something that just sits in the gaps between transactional episodes but actually facilitates the speakers and enhances their efficiency. This issue becomes one aspect of spoken interactions that has been examined by conversation analyst. It is the way a speaker and another (other) speaker(s) provide each other with feedback. Feedback is the way in which listeners show they are attending to what is being said. This can be done, for example, by the use of response tokens such as 'mm' and 'yeah', by paraphrasing what the other persons has just said, or through body position and the use of eye contact (Paltridge, 2006).

This study discusses the topic that has relation to the explanation above. It gives an insight into the importance of listener's role in Waiting for Godot drama and the ways the 
listeners signal that they pay attention to what being said by the speakers. It also discusses response tokens generally. It reveals what kinds and functions of response tokens found in the drama.

\section{REVIEW OF LITERATURE}

Response Tokens, based on the research of McCarthy (2003), are short utterances consists of a syllable, or a word, a phrase or a small sentence which uttered as a response of the primary speaker.

Uttering response tokens can be achieved if the speaker holds the floor. Holding the floor, as Young and Lee (2004) stated, means a speaker continues to speak and the other participants in the conversation choose not to take turns. The listener contributes to the turn by uttering words like 'mm', 'okay' or 'yeah' and also by gestures including head movements such as nodding. This is strengthened by McCarthy (1991) who said that if we use response tokens like yeah or $\mathrm{mm}$ with the purpose of giving attention to the speaker, listeners cannot use those words to interrupt the speaker. Response tokens cannot be used to initiate a conversation. It requires common expectations among participants about its appropriateness and a common willingness to take part in the talk. Response token, though thematically considered unimportant, is an essential aspect of conversation in that it provides a means of 'easing things along' (Schneider, 1988). People cannot arrange the amount of response tokens in their talks. It occurs naturally. This is proven in a research conducted by Jefferson (1984 in Gardner 2005). She found that some speakers of English use both Hmm and Yeah, whilst others use very few Hmms.

Several studies related to spoken conversation have been done by many reserchers, for examples: Duncan 2011 who focused on turn taking 'Some signals and Rules for Taking Speaking Turns in Conversation'; Tanaka 1999 'Turn-taking in Japanese Conversation: A Study in Gramar and Interaction; and adjacency pairs: 'Significance of Adjacency Pairs as Building Blocks of Social Interaction' by Garratt 2009; Analysing Conversational Data with Regards to Interactional Structures: Turn-Taking and Adjacency Pairs, also Face and Authority by Mullins 2012. Unfortunately, the study of verbal behaviors of the listeners by producing response tokens is rarely done and conducted.

There are types of response tokens proposed by McCarthy (2003) and functions of response tokens proposed by Gardner (2005). According to McCarthy (2003), there are several kinds of response tokens namely response tokens without expanded content, response tokens preceding expanded responses, response tokens with premodification, negative 
response tokens and doublets and also triplets tokens in short clause. There are also six functions of response tokens proposed by Gardner. They are continuers, acknowledgement, newsmaker, change-of-activity, assessment and brief question.

However, it is not always the case that an item of response token such as 'yeah' performs an acknowledging function in a conversation. Gardner (2005) shows that the item 'mm', for example, can perform many other functions as well. It may also serve to indicate a topic change instead of providing an acknowledging function, a recycling of a topic, or it may also solve a dispreferred action. The versatility of response tokens is also explained by Pomerantz (1984) in Gardner (2005), who said that an acknowledgement token like 'yeah' can be used for qualified agreements, but they can also be used for negative utterances. The function of response items such as 'mm', 'yeah' and 'okay' perform are also influenced by the place and timing of the utterance, or the context.

\section{RESEARCH METHODS}

In conducting this study, the researcher used qualitative approach to obtain rich description and to obtain response tokens in the play. The data was taken from the written form of Waiting for Godot drama written by Samuel Beckett which was published in 1994. The researcher only took the data from the conversation between Vladimir and Estragon because they uttered most response tokens utterances which are relevant with this study. The data of this study were the words, expressions, phrases, or small sentences produced by Vladimir and Estragon.

\section{RESULTS AND DISCUSSIONS}

\subsection{Types of Response Tokens used in Waiting for Godot}

The findings reveals that the most tokens uttered in Vladimir's and Estragon's utterances are response tokens without expanded content that appear mostly in their conversation with total number eighty three (83) tokens or thirty nine percent (39\%) from the whole data; Sixty seven (67) tokens or thirty three percent (33\%) tokens appear in type of response tokens preceding expanded response; fifty two (52) tokens or twenty three percent (23\%) occur in doublet and triplet tokens type; ten (10) tokens or four percent (4\%) appear as negative response tokens; response tokens with premodification type occurs least of all in one percent $(1 \%)$ or three (3) tokens. 


\subsubsection{Response Tokens without Expanded Content}

Response token without expanded content is a single response token type that occurs as the whole response move. In Vladimir and Estragon's utterance, there are eighty three (83) tokens of the first type or thirty nine percent (39\%) from the whole data. The data below is an example of response token without expanded content:

Vladimir: One out of four. Of the other three two don't mention any thieves at all and the third says that both of them abused him.

Estragon: Who?

Vladimir: What?

Estragon: What's all this about? Abused who? (Beckett, 1994:7)

There are two response tokens without further content type in this fragment. Both Estragon and Vladimir utter the same type of response token, single response token without expanded content "who?" and "what?".Although it is only a word, the response tokens uttered by both of them indicate the interactional concerns that listeners attend to. The token "what?" is uttered after token "who?". Estragon says "who?"because she does not understand about who is abused by the thieves. However, Vladimir's response is also a signal of him not understanding Estragon's question. He uses token "what?" because he does not know what the Estragon's question "who?" means.

\subsubsection{Response Tokens Preceding Expanded Response}

This type of token is a response token followed by further content in that listener's turn. There are sixty seven (67) tokens appearing in this type or thirty three percent (33\%) from the total response tokens in Vladimir's and Estragon's utterance. There is one of response tokens preceding expanded response data:

Vladimir: (gloomily). It's too much for one man. (Pause. Cheerfully) On the other hand what's the good of losing heart now, that's what I say. We should have thought of it a million years ago, in the nineties.

Estragon: Ah stop blathering and help me off with this bloody thing. (Beckett, 1994:3)

A response token "ah" in Estragon's utterance precedes expanded response "stop blathering and help me off with this bloody thing". The token "ah" appears as an indication that the interlocutor hears something inapposite with his current situation. Estragon wants to take off something which appears to be his boot. It is hard to remove so when Vladimir verbose about what they should have thought about, Estragon does not want to continue the topic because she is busy with the "bloody thing", by uttering response token "ah" and expanded response after the token. The writer found 18 tokens "ah" in this drama, the second most uttered response tokens including the one in this datum. 


\subsubsection{Response Tokens with Premodification}

This is the least type of tokens that appear in Vladimir's and Estragon's utterance. There are only three (3) tokens of the third response tokens type or one percent (1\%) from the whole data. Response tokens with premodificationoccur premodified by adverb of degree. In the data analyzed, some tokens are premodified by very. The data below is one of the example of this token:

Pozzo : How did you find me? (Vladimir and Estragon look at him blankly.) Good? Fair? Middling?Poor?Positively bad?

Vladimir: (first to understand). Oh very good, very very good. (Beckett, 1994:51)

Based on the dialogue above, Vladimir utters a response token "oh very good, very very good". It is a response tokens with premodifier "very" which intensifies their interactional and affective meanings to the talk. The token is actually a combination of the token "oh" and "very good, very very good". The token "oh" signifies that he immediately know what to say about Pozzo's performance and it is followed by token "very good, very very good" as his valuation. Vladimir seems wanting to satisfy Pozzo since he repeats the premodifier "very" three times. The premodifier "very" is a signalof stronger adjective word "good".

\subsubsection{Negative Token}

Negative token is a response token that appears to be negated with a post modifier "not". In Vladimir's and Estragon's utterance, there are ten (10) negative response tokens or four percent (4\%) from the whole response tokens in the main characters' utterance. The data below is one of negative response tokens:

Vladimir: And it's not over.

Estragon: Apparently not. (Beckett, 1994:45)

Estragon utters the token "apparently not" where the token is followed by postmodifier "not". It provides an effective way of affective response without any expanded response and simultaneously it reinforces the conversation more than just "no". It indicates that Estragon judges on the topic that Vladimir conveys, even though Vladimir also does the valuation. The word "apparently" added with "no" makes a stronger comment of negation in the utterance.

\subsubsection{Doublet and Triplet Tokens in Short Clauses}

Doublet is response tokens that consist of two words whereas triplet consists of three words response tokens. There are fifty two (52) response tokens or twenty three percent (23\%) appear in doublet and triplet type. One of data of doublet and triplet in Vladimir's and Estragon's utterance is proposed below:

Vladimir: Where was I . . How's your foot? 
Estragon: Swelling visibly.

Vladimir: Ah yes, the two thieves. Do you remember the story? (Beckett, 1994:6)

The first data is shown in this dialogue. There is a doublet token "ah yes" uttered by Vladimir. By using token "ah" and "yes" along, it can signal a strong relation between the producer and the previous interlocutor. Vladimir utters response tokens because he remembers something to tell to Estragon, it is the story of two thieves. It is quite queer because a response to someone who feels hurt must be a sad response. However Vladimir chooses to forget it and tells Estragon another story. This shows the intimacy between the main characters and oddity of the drama.

\subsection{Functions of Response Tokens in Waiting for Godot}

The findings show that brief question functions appear mostly in the Vladimir's and Estragon's utterance with total sixty nine (69) tokens or thirty three percent (33\%) from the whole data; acknowledgement functions occur sixty two (62) times or twenty nine percent (29\%); assessment function tokens appear thirty seven (37) times or seventeen percent (17\%); newsmarker functions occur thirty two (32) times or fifteen percent (15\%); continuers functions appear ten (10) times or four percent (4\%); change-of-activity functions occur least of all with only five (5) tokens or two percent (2\%).

\subsubsection{Continuers Token}

Continuers are used by recipients to show that he or she understands that the speech is on progress but is not yet completed. This research found that there are ten (10) tokens or only four percent (4\%) from the whole Vladimir's and Estragon's utterance which all of them appear as token "well?".The data below is one ofcontinuers tokens:

Vladimir: You're not unhappy? (The Boy hesitates.) Do you hear me?

Boy : Yes Sir.

Vladimir: Well?

Boy $\quad$ : I don't know, Sir. (Beckett, 1994:77)

Based on dialogue above, a continuer response token "well?" is uttered by Vladimir. It has function to signify what Vladimir wants. He wants to give the boy opportunity to speak. The token expresses the listener's strong response of curiosity. It gives signal that Vladimir pays attention to what being said by the boy. Vladimir does not hold the floor, but he gives the floor back to the boy. However, the boy does not know what to talk. Vladimir feels that he is not given attention by the boy, thus he utters the response token "well?"

\subsubsection{Acknowledgement Token}

Acknowledgement is the function of response token that aligns, agrees and confirms the prior speaker's talk. In Vladimir's and Estragon's utterance, there are sixty two (62) tokens or 
twenty nine percent (29\%) from the total tokens. Below is one of the data of acknowledgement tokens:

Estragon: That wasn't such a bad little canter.

Vladimir: Yes, but now we'll have to find something else. (Beckett, 1994:96)

It is a response token "yes" which signifies that the recipient agrees on the primary speaker's utterance and he does not have any problem in understanding the utterance. Estragon says that something was not such a bad little canter. Vladimir agrees on him and utters the response token "yes". However, the content after the response shows suggestion that Vladimir has different opinion with Estragon since he utters a word "but" and proposes a new action indicated by words "find something else"

\subsubsection{Newsmarker Token}

Newsmarker is a function of tokens which mark the prior speaker's turn as newsworthy in some way. There are thirty two (32) tokens or fifteen percent (15\%) from the whole response tokens data uttered by Vladimir and Estragon. Here is one of the data of newsmarker tokens:

Estragon: I'm tired! (Pause.) Let's go.

Vladimir: We can't.

Estragon: Why not?

Vladimir: We're waiting for Godot.

Estragon: Ah! (Pause. Despairing) What'll we do, what'll we do! (Beckett, 1994:103)

Here, the response token "ah!" is also included in newsmarker function. However, Estragon utters the response token indicating that there is something inapposite with Vladimir's utterance. The act of uttering response token "ah!" can be caused by Estragon's despair of what they should do. Estragon cannot bear to wait and decide to leave. However Vladimir always reminds her to be patient by saying that they cannot leave their place. Thus, Estragon utters the token "ah!"

\subsubsection{Change-of-Activity Token}

Change-of-activity tokens is tokens which mark a transition to new activity or a new topic in the talk. In Vladimir's and Estragon's utterance, this function is the least where there are only five (5) tokens or two percent (2\%) from the total tokens. Below is one of the data of change-of-activity tokens:

Vladimir: You're as bad as myself. (Silence.) Where do you sleep?

Boy $\quad$ : In the loft, Sir.

Vladimir: With your brother?

Boy : Yes Sir.

Vladimir: In the hay?

Boy : Yes Sir. (Silence.)

Vladimir: All right, you may go. (Beckett, 1994:75) 
One of change-of-activity function of response token in Vladimir's utterance is a response token "all right". It has function to change the activity. Even though the token usually marks a transition to new activity or a new topic in the talk, in that case the token indicates that Vladimir wants to stop his conversation with the boy in the fragment above. It seems that both Vladimir and the boy cannot keep the conversation anymore. Thus, he utters the token corroborated with the expanded response "you may go".

\subsubsection{Assessment Token}

Assessment is the function which evaluates the talk of the prior speakers. There are thirty seven (37) tokens or seventeen percent (17\%) from the whole response tokens data uttered by Vladimir and Estragon. The data below is one of the data of assessment tokens:

Vladimir: Because he wouldn't save them.

Estragon: From hell?

Vladimir: Imbecile! From death.

Estragon: I thought you said hell.

Vladimir: From death, from death.

Estragon: Well what of it? (Beckett, 1994: 8)

The data above shows that assessment token occurs in that fragment. Vladimir utters a response token "Imbecile!" which is included in assessment function. The token is reinforced with further content "From death" which is the answer of Estragon's question. The token "Imbecile!" evaluates the talk of the prior speaker, in this case is Estragon. This token has the added sense of expressing the listener's reaction to the current turn. In the dialogue, Vladimir says "Imbecile!" because he criticizes Estragon of misunderstanding what he says before. It indicates Vladimir's established relationship with Estragon because he says it without feeling sorry.

\subsubsection{Brief Question Token}

Brief question is the function of response token used for clarification or other types of repair, and it seeks to clarify mishearing or misunderstanding. There are sixty nine (69) tokens or thirty three percent (33\%) from the total tokens. Below is one of the data of brief question tokens:

Vladimir: Suppose we repented.

Estragon: Repented what?

Vladimir: Oh ... (He reflects.) We wouldn't have to go into the details. (Beckett, 1994: 5)

Brief question token appears in Estragon's turn of talk. In this dialogue, Estragon utters doublet token "repented what?" which is the repetition of Vladimir's verb. The function of the 
token is brief question token that attempts to clarify misunderstandings. This token signals the listener's strong response of his curiosity toward the primary speaker's utterance. Estragon says the token because he is still not clear about repenting idea suggested by Vladimir.

\section{CONCLUSION}

The analysis of the data gives some knowledge about the kinds and functions of response tokens uttered by Vladimir and Estragon in drama Waiting for Godot. The findings of this research strengthen McCarthy's (2003) and Gardner's (2005) opinions about types and functions of response tokens.

Overall, the findings reveal that Vladimir and Estragon use response tokens in their utterance to provide feedback to the prior speaker. The tokens have several types including response tokens without expanded content, response tokens preceding further response, response tokens with premodification, negative response tokens and doublet and also triplet tokens which are proposed by McCarthy (2003). Those different types indicate the utterer's concerns toward the talk they attend. Some tokens followed by further content or some tokens repeated shows that the utterer of response token pay more attention to the previous speaker rather than uttering a single token only.

The writer concludes that response tokens uttered by Vladimir and Estragon express their affective response of surprise, disbelief, curiosity and so forth such as "impossible", "oh", "pardon?", "yes yes" and so on. It is derived from McCarthy's (2003) view on the usage of response tokens.

Besides, this study also finds that the token "yes" is the most often uttered response tokens among other tokens in the utterance of Vladimir and Estragon. Most often uttered response tokens "yes" show the tendency of Vladimir and Estragon in agreeing the previous utterance. Occasionally, the token "yes" is reinforced by expanded contents, which are responses to an argument by the primary speaker.

It is a fact that a response token can have two different functions. This is found in token "well" within the utterance of the main characters which functions as continuers and acknowledgement. The token "well" added by question mark indicates that either Vladimir or Estragon wants to let the previous speaker talk more. The writer concludes that "well?" is included in continuers function of token, derived from Gardner's view (2005) that continuers are used to pass up the opportunity of talking toward the prior speaker. Meanwhile, the token "well" without question mark and always followed by further content indicates that the main 
characters understand what being said by the previous speaker and pay attention to whom they talk to.

In conclusion, the findings of this research have contributed to the importance of the listener and response tokens in use. Response tokens are important since they are used to give some signals indicating that they pay attention to the previous speaker. It makes the previous speaker feels respected since the speaker does not ignore him/her and thus, the conversation is maintained better.

\section{REFERENCES}

Beckett, S. (1953). Waiting for Godot. London: Faber and Faber.

Duncan, Starkey. (2011). Some signals and Rules for Taking Speaking Turns in Conversation. Chicago: University of Chicago.

Gardner, Rod. (2005). When Listeners Talk: Response Tokens and Listener Stance. Philadelphia: John Benjamin Publishing.

Garratt, J.E. (2009). Significance of Adjacency Pairs as Building Blocks of Social Interaction. Colchester: University of Essex.

Jefferson, Gail. (1984). Notes on a systematic deployment of the acknowledgement tokens „yeah"e and „mm hme. Papers in Linguistics 17 (2): 197-216

McCarthy, Michael. (1991). Discourse Analysis. Cambridge: Cambridge University Press.

McCarthy, Michael. (2003). Talking Back: "Small" Interactional Response Tokens in Everyday Conversation. Nottingham: Lawrence Erlbaum Associates. 36(1), 33-63.

Mullins, Joanna. (2012). Analysing Conversational Data with Regards to Interactional Structures: Turn-Taking and Adjacency Pairs, also Face and Authority. Colchester: University of Essex.

Paltridge, Brian. (2006). Discourse Analysis - An Introduction. London: Continuum.

Pomerantz, Anita. (1984). Agreeing and disagreeing with assessments: Some features of preferred/dispreferred turn shapes. In Atkinson and Heritage (eds), 57-101.

Schiffrin, Deborah. (1987). Discourse Markers. Cambridge: Cambridge University Press.

Schneider, Klaus P. (1988). Analyzing Phatic Discourse. Marburg: Hitzeroth.

Tanaka, Hiroko. (1999). Turn-taking in Japanese Conversation: A Study in Gramar and Interaction. Philadelphia: John Benjamin Publishing.

Young and Lee. (2004). Identifying Units in Interaction: Reactive Tokens in Korean and English Conversation. Journal of Sociolinguistics 8/3, 380- 407 Oxford: Blackwell Publishing. 